\title{
Jean Sgard, Vie de Prévost (1697-1763)
}

\section{Franco Piva}

\section{(2) OpenEdition}

\section{Journals}

\section{Edizione digitale}

URL: https://journals.openedition.org/studifrancesi/45882

DOI: 10.4000/studifrancesi.45882

ISSN: 2421-5856

\section{Editore}

Rosenberg \& Sellier

\section{Edizione cartacea}

Data di pubblicazione: 1 octobre 2007

Paginazione: 447-448

ISSN: 0039-2944

\section{Notizia bibliografica digitale}

Franco Piva, «Jean Sgard, Vie de Prévost (1697-1763)», Studi Francesi [Online], 152 (LI | II) | 2007, online dal 30 novembre 2015, consultato il 24 novembre 2021. URL: http://journals.openedition.org/ studifrancesi/45882 ; DOI: https://doi.org/10.4000/studifrancesi.45882

Questo documento è stato generato automaticamente il 24 novembre 2021.

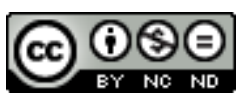

Studi Francesi è distribuita con Licenza Creative Commons Attribuzione - Non commerciale - Non opere derivate 4.0 Internazionale. 


\title{
Jean Sgard, Vie de Prévost (1697-1763)
}

\author{
Franco Piva
}

\section{NOTIZIA}

JEAN SGARD, Vie de Prévost (1697-1763), Les Presses de l'Université de Laval, 2006 («Les

Collections de la République des Lettres, Etudes»), pp. 296.

1 È possibile scrivere la biografia di uno scrittore, come Prévost, che ha lasciato dietro di sé pochissime tracce certe della sua esistenza, e la cui esistenza è stata, fin da subito, avvolta da una sorta di leggenda che ne ha nascosto i tratti più autentici e portato a identificare la sua vita con quella dei suoi personaggi? Quale atteggiamento deve assumere colui che decide di ricostruire la biografia di questo uomo, tentando di ritrovare, al di là dello scrittore e dei personaggi da lui creati, al di là anche dei biografi che lo hanno preceduto, e che troppo spesso hanno ceduto alla tentazione dell'agiografia o della denigrazione, l'uomo che fu in realtà Antoine-François Prévost? È con queste difficoltà che si è confrontato Jean Sgard quando ha deciso, o accettato, di scrivere questa Vie de Prévost; d'altra parte chi, se non lui, poteva raccogliere una simile sfida, lui che da più di quarant'anni ha non solo studiato con la passione e l'acutezza che tutti gli riconoscono l'opera di Prévost, ma inseguito anche con ostinazione le tracce della sua esistenza, proprio nel tentativo di dare all'autore di Manon Lescaut e di Cleveland contorni più precisi e sicuri di quanto non avessero fatto coloro che avevano creduto di riempire i «buchi» che la vita di Prévost in effetti presenta con la vita dei suoi personaggi; oppure da coloro che, in opposizione alla leggenda nera che aveva presto avvolto e stravolto Prévost, hanno cercato con ostinazione le tracce del «bon abbé» Prévost? Nella piena coscienza delle difficoltà e dei rischi che un'impresa del genere comportava.

2 Per evitarli Sgard ha proceduto innanzitutto a una attenta valutazione dei documenti, pochi per la verità e spesso frammentari, che di Prévost ci sono rimasti. «Tous les documents - ha precisato egli stesso nell'Introduction - ont été soumis à l'analyse de texte, recoupés, contextualisés afin de [leur faire] livrer toutes les informations qu'ils 
détenaient». Trattandosi di una «vie d'écrivain», che non ha «d'intérêt que par rapport à l'œuvre du romancier», egli non ha poi potuto non fare «entrer en jeu l'élaboration de cette œuvre, les circonstances de la publication, le travail même de l'écrivain», tanto più che, a mano a mano che il lavoro avanzava, gli è parso sempre più chiaro che «la seule chose qui comptait dans la vie de Prévost était son œuvre romanesque et que toutes les péripéties de son existence étaient reliées de près ou de loin à cette décision de vivre, envers et contre tous, de son œuvre», con la conseguenza che "tous les détails de sa vie privée [étaient] susceptibles d'entrer dans la composition de ses romans». Se questo ha portato a definire con esattezza il rapporto «entre les faits et leur traitement romanesque», non ha però significato, per Jean Sgard, cedere alla tentazione di vedere nella vita di Prévost una vita "de héros», segnata da un destino superiore, anche se è apparso presto evidente che si trattava di una vita spesso enigmatica.

3 Nella sua minuziosa «enquête» Sgard è partito proprio alla ricerca di quello che sta dietro o al di là dell'enigma: con la caparbietà del detective, ma anche con la distanza dello storico e la tranquillità dello studioso convinto di aver fatto quanto era umanamente possibile per restituire di Prévost l'immagine più vicina a quella verità assoluta, o oggettiva, che forse non esiste e che a ogni modo non sarà mai dato all'uomo, a nessun uomo, di raggiungere. «La vie de Prévost, telle qu'on la lira ici, osserva in conclusione Sgard - est donc un récit, mais c'est avant tout le récit d'une recherche, sans drames, sans péripéties, sans roman. Il m'a semblé que la vie de Prévost n'avait pas l'unité d'un destin, mais qu'elle se présentait constamment comme une énigme à déchiffrer, qu'elle reposait sur un secret et un malentendu». Se l'enigma non è stato, forse, ancora del tutto risolto, è indubbio che molti dei malintesi che pesavano sulla vita e sulla figura di Prévost sono stati definitivamente chiariti. Il Prévost restituitoci da Sgard, senza essere rivoluzionario, è in parte almeno diverso da quello che ci avevano proposto i biografi, pur lodevoli, che l'avevano preceduto, più semplice e più complesso nello stesso tempo, certamente più vero e più vicino a quello strano uomo che, per la prima volta forse nella storia della letteratura francese, s'investì totalmente nell'opera e nei personaggi che venne via via componendo, pur non identificandosi mai totalmente con ciascuno, o qualcuno di essi. 